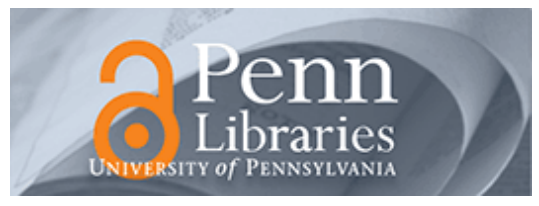

University of Pennsylvania

ScholarlyCommons

Finance Papers

Wharton Faculty Research

5-1983

\title{
An Intertemporal Model of Saving and Investment
}

Andrew B. Abel

University of Pennsylvania

Olivier J. Blanchard

Follow this and additional works at: https://repository.upenn.edu/fnce_papers

Part of the Finance and Financial Management Commons, and the Taxation Commons

\section{Recommended Citation}

Abel, A. B., \& Blanchard, O. J. (1983). An Intertemporal Model of Saving and Investment. Econometrica, 51 (3), 675-692. Retrieved from https://repository.upenn.edu/fnce_papers/166

This paper is posted at ScholarlyCommons. https://repository.upenn.edu/fnce_papers/166

For more information, please contact repository@pobox.upenn.edu. 


\title{
An Intertemporal Model of Saving and Investment
}

\begin{abstract}
The standard model of optimal growth, interpreted as a model of a market economy with infinitely longlived agents, does not allow separation of the savings decisions of agents from the investment decisions of firms. Investment is essentially passive: the "one good" assumption leads to a perfectly elastic investment supply; the absence of installation costs for investment leads to a perfectly elastic investment demand. On the other hand, the standard model of temporary equilibrium used in macroeconomics characterizes both the savings-consumption decision and the investment decision, or, equivalently, derives a well-behaved aggregate demand which, in equilibrium, must be equal to aggregate supply. Often, however, we want to study the movement of the temporary equilibrium over time in response to a particular shock or policy. The discrepancy between the treatment of investment in the two models makes imbedding the temporary equilibrium model in the growth model difficult. This paper characterizes the dynamic behavior of the optimal growth model with adjustment costs. It shows the similarity between the temporary equilibrium of the corresponding market economy and the short-run equilibrium of standard macroeconomic models: consumption depends on wealth, investment on Tobin's q. Equilibrium is maintained by the endogenous adjustment of the term structure of interest rates. It then shows how the equivalence can be used to study the dynamic effects of policies; it considers various fiscal policies and exploits their equivalence to technological shifts in the optimal growth problem.
\end{abstract}

\section{Disciplines}

Finance and Financial Management | Taxation 
NBER WORKING PAPER SERIES

AN INTERTEMPORAL MODEL OF SAVING AND INVESTMENT

\author{
Andrew B. Abel \\ Olivier J. Blanchard \\ Working Paper No. $\underline{885}$ \\ NATIONAL BUREAU OF ECONOMIC RESEARCH \\ 1050 Massachusetts Avenue \\ Cambridge MA 02138
}

April 1982

The research reported here is part of the NBER's research program in Economic Fluctuations. Any opinions expressed are those of the authors and not those of the National Bureau of Economic Research. 


\section{NBER Working Paper 非85}

April 1982

An Intertemporal Model of Saving and Investment

\section{ABSTRACT}

The standard model of optimal growth, interpreted as a model of a market economy with infinitely long-lived agents, does not allow separation of the savings decisions of agents from the investment decisions of firms. Investment is essentially passive: the "one gooc" assumption leads to a perfectly elastic investment supply; the absence of installation costs for investment leads to a perfectly elastic investment demand.

on the other hand, the standard model of temporary equilibrium used in macroeconomics characterizes both the savings-consumption decision and the investment decision, or, equivalently, derives a well-behaved aggregate demand which, in equilibrium, must be equal to aggregate supply.

often, however, we want to study the movement of the temporary equilibrium over time in response to a particular shock or poifcy. The discrepancy between the treatment of investment in the two models makes imbedaing the temporary equilibrium model in the growth model difficult. This paper characterizes the dynamic behavior of the optimal growth model with adjustment costs. It shows the similarity between the temporary equilibrium of the corresponding market economy and the short-run equilibrium of standard macroeconomic models: consumption depends on wealth, investment on Tobin's q. Equilibrium is maintained by the endogenous adjustment of the term structure of interest rates. It then shows how the equivalence can be used to study the dynamic effects of policies; it considers various fiscal policies and exploits their equivalence to technological shifts in the optimal growth problem.

Andrew B. Abel Olivier J. Blanchard Department of Economics Harvard University Cambridge, MA 02138 (617) 495-1869 


\section{Introduction}

The standard model of optimal growth, interpreted as a model of a market economy with infinitely long-lived agents does not allow separation of the savings decisions of agents from the investment decisions of firms. Investment is essentially passive: the "one good" assumption leads to a perfectly elastic investment supply; the absence of installation costs for investment leads to a perfectly elastic investment demand.

On the other hand, the standard model of temporary equilibrium used in macroeconomics, such as the Metzler [6] model for example, characterizes both the savings-consumption decision and the investment decision, or, equivalently, derives a well-behaved aggregate demand which, in equilibrium, must be equal to aggregate supply.

Often, however, we want to study the movement of the temporary equilibrium over time in response to a particular shock or policy. The discrepancy between the treatment of investment in the two models makes imbedding the temporary equilibrium model in the growth model difficult. This is a particularly serious problem if the assumption of rational expectations is made, as in this case expected future events affect the current equilibrium and it becomes impossible to characterize the current equilibrium without using an intertemporal model.

The obvious solution is to modify the optimal growth model by relaxing one of the two assumptions which imply passive investment behavior. This can be done either by introducing a two-sector technology which generates a we11-defined investment supply function (Srinivasan [7], Uzawa [9]), or it can be done by introducing installation or adjustment costs which generate a well-defined investment demand function. The purpose of this paper is to characterize the dynamic behavior of the optimal growth model 
with adjustment costs, to show the similarity between the temporary equilibrium of the corresponding market economy and the temporary equilibrium of standard short-run macroeconomic models, and finally to show how easily this model can be used to study the dynamic effects of shocks or policies. The paper is organized as follows:

Section 2 sets up and solves the optimal growth problem of an economy with adjustment costs.

Section 3 characterizes the behavior of agents and firms in a market economy which replicates the centralized economy described in section 2 . Consumption decisions are made by intertemporally optimizing households; at any point of time consumption is an increasing function of total wealth, including human capital, evaluated at market interest rates. Investment decisions are made by value-maximizing firms; at any point in time investment is an increasing function of the shadow price of capital, in a manner similar to Tobin's [8] q. The equality of saving and investment is maintained at every point in time by the endogenous adjustment of current and future market interest rates. The temporary equilibrium in this model is similar to the standard IS relation of many short-run macro models.

Section 4 formally provesthe equivalence of the centralized and market economies.

Sections 5 and 6 use this equivalence to study the effects of various fiscal policies. To do this, we use the equivalence of these fiscal policies in the market economy to technology shifts in the centralized economy. We consider five different policies, lump-sum taxes, proportional taxes on gross output, profit or consumption, and investment tax credits. The proceeds of these taxes are either used for government spending or 
redistributed in lump-sum rebates. Section 5 shows equivalence and steadystate effects. Section 6 studies the dynamic effects of lump-sum and consumption taxes, depending on whether they are anticipated or unanticipated, and whether the economy is in or out of steady state. 


\section{The Centralized Economy}

The central planning problem is the following:

$2.1 \max _{c_{t}} \int_{0}^{\infty} U\left(c_{t}\right) e^{-\beta t} d t \quad$ subject to:

$2.2 \quad f\left(k_{t}\right)=c_{t}+i_{t}\left(1+h\left(1_{t} / k_{t}\right)\right)$

$2.3 \quad \dot{\mathrm{k}}_{\mathrm{t}}=\mathrm{i}_{\mathrm{t}}-\delta \mathrm{k}_{\mathrm{t}} ; \mathrm{k}_{0}=\overline{\mathrm{k}}_{0}$

$\mathrm{U}^{\prime}(\cdot)>0, \mathrm{U}^{\prime \prime}(\cdot)<0, \mathrm{U}^{\prime}(0)=\infty$

$f^{\prime}(\cdot)>0, f^{\prime \prime}(\cdot)<0, f^{\prime}(0)=\infty$

$h(0)=0, h^{\prime}(\cdot)>0,2 h^{\prime}(\cdot)+\frac{i}{k} h^{\prime \prime}(\cdot)>0$

All variables are in per capita terms, with standard interpretations. This problem differs from the standard optimal growth problem orly because of the presence of costs of installation $h(\cdot)$. In order to undertake gross investment of $i$ units of capital, 1 units of output must be set aside to be installed as capital, together with $i h(i / k)$ units which are used during installation. Thus gross investment per capita at rate $i$ has an opportunity cost of $i(1+h(i / k))$ units of output. ${ }^{2}$ The properties of $h(\cdot)$ make the total installation cosi $i h(i / k)$ nonnegative, convex with a minimum value of zero, which is attained when gross investment is zero. An alternative formulation, which is as plausible, would make installation costs a function of net investment; the net investment formulation is sometimes technically more attractive, as it simplifies the characterization of the steady state and of local dynamics. 
The Hamiltonian for this problem is

$2.4 \quad e^{-\beta t}\left[U\left(f\left(k_{t}\right)-i_{t}\left(1+h\left(i_{t} / k_{t}\right)\right)\right)+y_{t}\left(i_{t}-\delta k_{t}\right)\right]$

where $y_{t}$ is the shadow price, measured in units of utility, of an additional unit of installed capital at time $t$.

The optimality conditions, ${ }^{3}$ defining $x_{t} \equiv\left(i_{t} / k_{t}\right)$ and $H\left(x_{t}\right) \equiv$ $1+h\left(x_{t}\right)+x_{t} h^{\prime}\left(x_{t}\right)$, are:

2.5

$$
U^{\prime}\left(c_{t}\right) H\left(x_{t}\right)=y_{t}
$$

2.6

$$
\dot{y}_{t}=(\beta+\delta) y_{t}-U^{\prime}\left(c_{t}\right)\left[f^{\prime}\left(k_{t}\right)+x_{t}^{2} h^{\prime}\left(x_{t}\right)\right]
$$

$2.7 \quad \lim _{t \rightarrow \infty} e^{-\beta t} y_{t} k_{t}=0$

Consider (2.5) first. $H\left(x_{t}\right)$ is the marginal opportunity cost of investment. Thus the condition states that this marginal cost measured in units of utility must be equal to $y$.

Consider (2.6). $x_{t}^{2} h^{\prime}\left(x_{t}\right)$ is the reduction in the opportunity cost of installation $i_{t} h\left(i_{t} / k_{t}\right)$ made possible by an additional unit of capital. Therefore $f^{\prime}\left(k_{t}\right)+x_{t}^{2} h^{\prime}\left(x_{t}\right)$ is the total marginal product of capital. Solving (2.6) subject to the transversality condition (2.7) gives:

$$
2.8 \quad y_{t}=\int_{t}^{\infty} U^{\prime}\left(c_{s}\right)\left[x_{s}^{2} h^{\prime}\left(x_{s}\right)+f^{\prime}\left(k_{s}\right)\right] e^{-(\beta+\delta)(s-t)} d s
$$


This states that $y_{t}$ in turn must be equal to the present discounted value of marginal products, also measured in units of utility.

\section{Steady state and dynamics}

If $\dot{\mathrm{y}}=\dot{\mathrm{k}}=0, \mathrm{x}_{\mathrm{SS}}=\delta$ and the steady-state capital stock is given by a modified "modified golden rule": $\mathrm{f}^{\prime}\left(\mathrm{k}_{\mathrm{sS}}\right)+\delta^{2} \mathrm{~h}^{\prime}(\delta)=$ $(\beta+\delta)\left(1+h(\delta)+\delta h^{\prime}(\delta)\right)$. This implies $f^{\prime}\left(k_{s s}\right)>(\beta+\delta)$. This comes from installation costs which make the opportunity cost larger than in the standard optimal growth model.

The system $(2.3,5,6)$ is a dynamic system in $(k, y, x)$ where either $y$ or $\mathrm{x}$ can be eliminated. Although $\mathrm{y}$ plays an important conceptual role, it is more useful to characterize the dynamics in terms of $(k, x)$ as the movement of $k, x$ and $c$ can be directly obtained from the phase diagram. Eliminating $c_{t}$ in (2.5) using (2.2), differentiating (2.5) with respect to time and eliminating $\dot{y}_{t}$ using (2.6) gives:

2.9

$$
\begin{gathered}
{\left[H^{\prime}(x)-\frac{U^{\prime \prime}(c)}{U^{\prime}(c)}(H(x))^{2} k\right] \dot{x}=\left[(\beta+\delta) H(x)-x^{2} h^{\prime}(x)-f^{\prime}(k)\right]} \\
-\frac{U^{\prime \prime}(c)}{U^{\prime}(c)} H(x)\left[f^{\prime}(k)-x(1+h(x))\right] \dot{k}
\end{gathered}
$$

This equation, together with $\dot{k}=k(x-\delta)$, characterizes the equations of motion. The complete characterization is done in the appendix; the results are displayed in Figures I and II.

The steady state is a saddle point equilibrium. The transversality condition requires the system to be on the unique stable path. Convergence of $\mathrm{x}$ and $\mathrm{k}$ to their equilibrium values is monotonic. Figure II draws iso- 


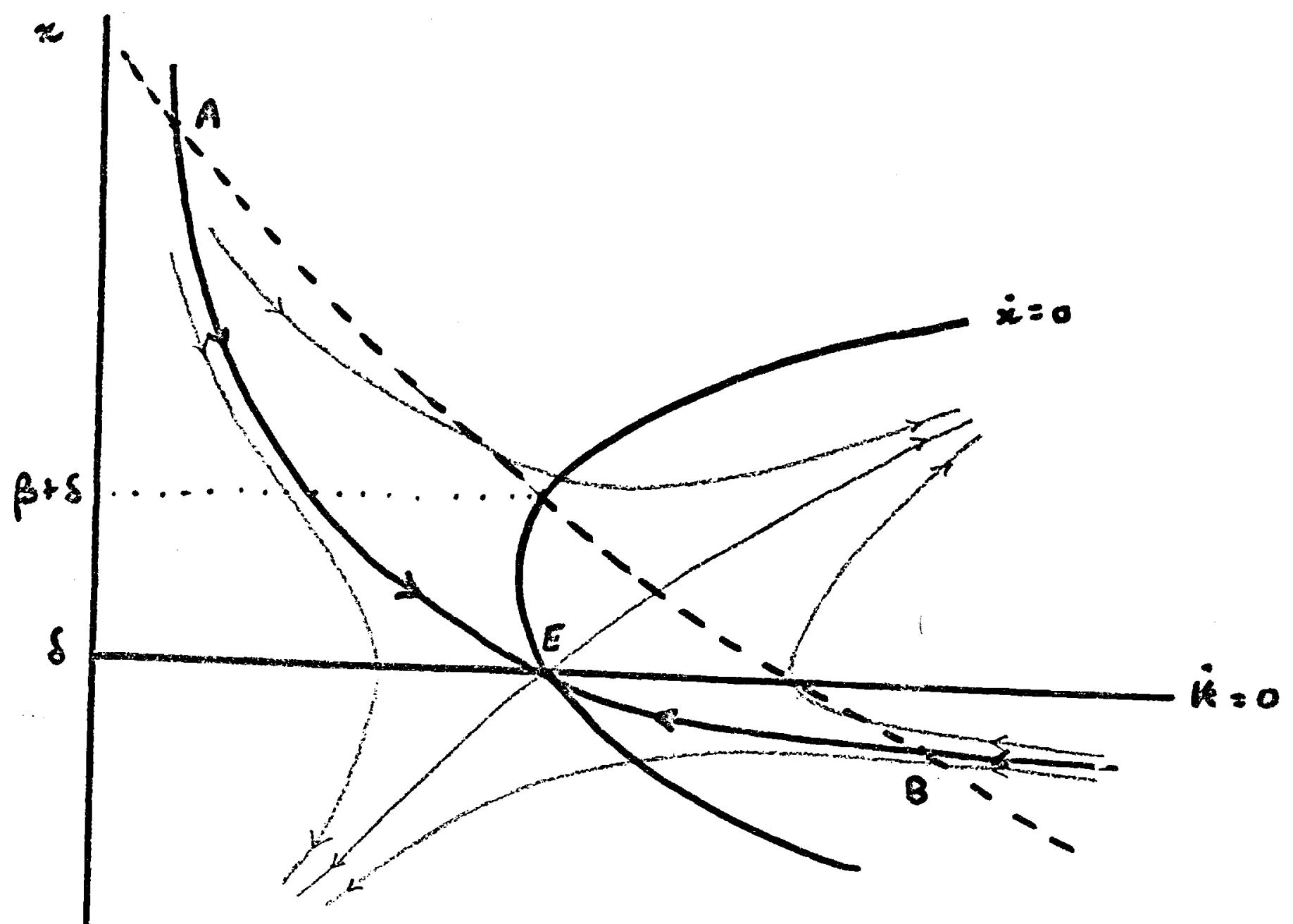

6

Figure I. 


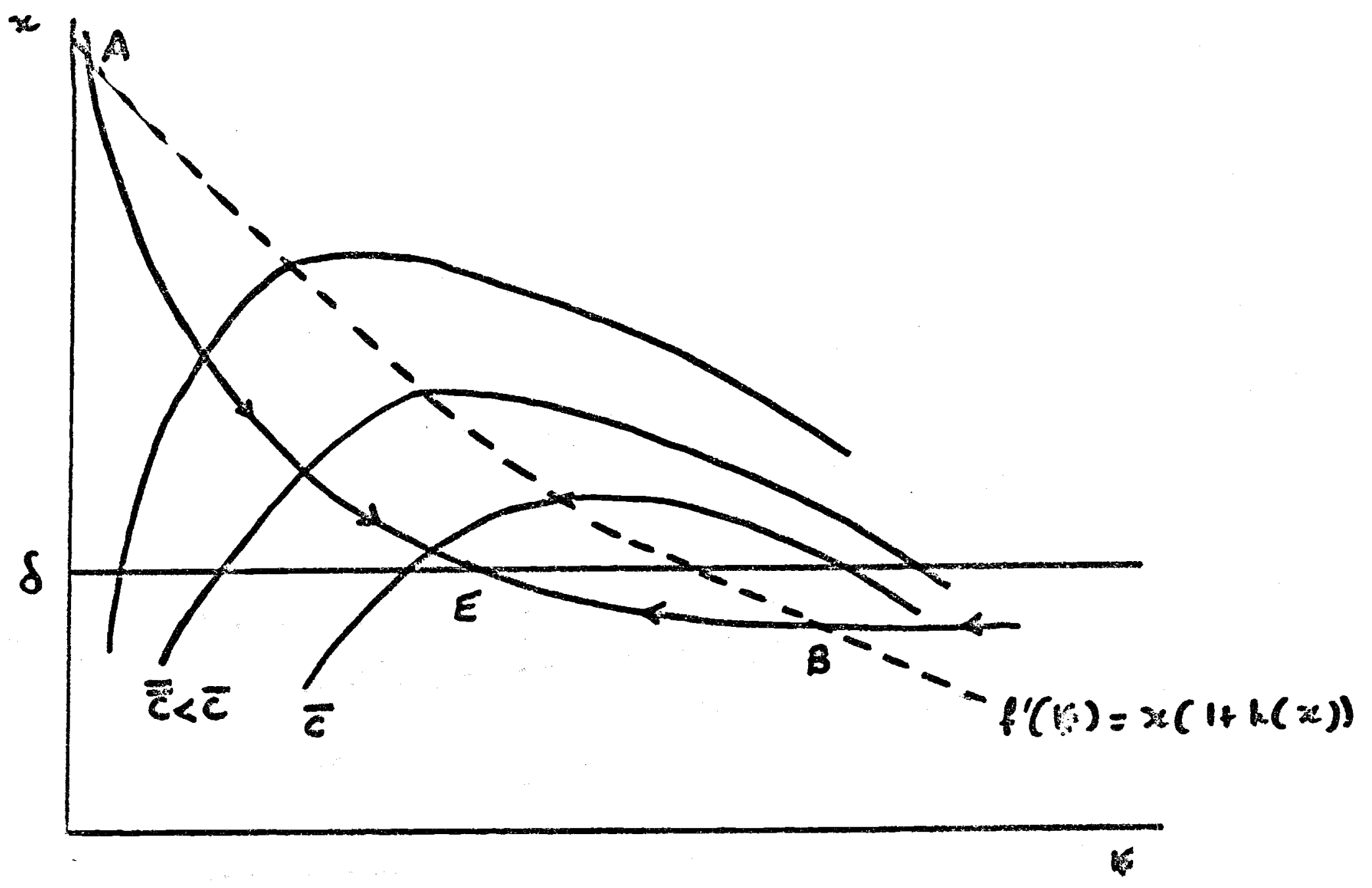

Figere II 
consumption loci. Iso-consumption loci satisfy: $f(l)-k x(1+h(x))=$ constant and for a given $x$, reach their maximum at $k$ such that $f^{\prime}(k)=$ $x(1+h(x))$. This allows us to characterize the behavior of consumption in Figure I, at least between points $A$ and $B$. Consumption is monotonically increasing when the steady state is approached from the northwest, monotonically decreasing when the steady state is approached from the southeast. 


\section{The Market Economy.}

We now consider an economy in which agents have the same utility function and firms the same technology as in the previous section. We characterize the maximization problem of firms and agents and show the role of the sequence of interest rates in clearing the goods market.

\section{Value maximization by firms}

Production is carried out by many identical competitive firms. For notational simplicity, the number of firms is equal to the number of agents so that the same symbol denotes the ratio of a variable per capita or per firm.

Each firm faces a time path of interest rates $\left\{r_{t}\right\}_{t=}=[0, \infty)$
\[ -\int^{t} r_{v} d v \] discount factor $\rho_{t} \equiv e^{\circ}$ gives the rate at which output at time $t$ can be traded for output at time zero.

For simplicity, we do not explicitly model the labor market. As 1abor is in fixed supply, labor market equilibrium and the above normalization imply that there will be one worker per firm, each firm facing a time path of wage bills $\left\{\mathrm{w}_{t}\right\}_{t=[0, \infty)}$. Thus the decision problem of the representative firm is to choose a time path of investment which maximizes the present value of its cash flow:

$$
\begin{aligned}
& v=\int_{0}^{\infty}\left[f\left(k_{t}\right)-i_{t}\left(1+h\left(i_{t} / k_{t}\right)\right)-w_{t}\right] \rho_{t} d t \text { subject to: } \\
& \dot{k}_{t}=i_{t}-\delta k_{t}
\end{aligned}
$$


The Hamiltonian for this problem is:

$$
\rho_{t}\left[f\left(k_{t}\right)-i_{t}\left(1+h\left(i_{t} / k_{t}\right)\right)-w_{t}+q_{t}\left(i_{t}-\delta k_{t}\right)\right]
$$

The optimality conditions, ${ }^{3}$ recalling the definitions of $x_{t}$ and $H\left(x_{t}\right)$, are

$3.1 \quad H\left(x_{t}\right)=q_{t}$

$$
\dot{q}_{t}=\left(r_{t}+\delta\right) q_{t}-\left[f^{\prime}\left(k_{t}\right)+x_{t}^{2} h^{\prime}\left(x_{t}\right)\right]
$$

$3.3 \quad \lim _{t \rightarrow \infty} \rho_{t} q_{t} k_{t}=0$

Consider (3.1) first. It states that investment takes place until the marginal cost of investing equals the shadow value of installed capital. As $\mathrm{H}^{\prime}(\cdot)>0$ the equation can be inverted to give $\mathrm{i} / \mathrm{k}$ as an increasing function of $\mathrm{q}$, in: a manner similar to Tobin's $\mathrm{q}$ theory of investment.

Condition (3.2) can be solved subject to the transversality condition (3.3) to give:

$3.4 \quad q_{t}=\int_{t}^{\infty}\left[x_{s}^{2} h^{\prime}\left(x_{s}\right)+f^{\prime}\left(k_{s}\right)\right] e^{-s_{t}^{s}\left(r_{v}+\delta\right) d v} d s$ The shadow price $\mathrm{q}$ is the present value of marginal products. Note the similarities and dissimilarities with equation (2.8) in the centralized economy: returns are measured in units of output, not in units of utility and the discount rate depends on the market-determined interest rate. 
After having paid wages to workers, the firm has to decide how to distribute profit and finance investment. It may finance investment by retaining earnings or by issuing shares or bonds. All financing schemes are equivalent in the sense that they lead to the same path of consumption and investment; they differ, however, in terms of institutional arrangements. A notationally and conceptually simple financing scheme is that firms finance investment by retaining earnings and never issue new shares or bonds. In this case, equilibrium personal savings would be zero at every point in time. Note also that in the absence of a bond market, interest.. rates would not be directly observable.

We adopt a slightly different scheme, in which firms finance themselves both by retaining earnings and by issuing new bonds. Specifically, replacement investment is financed out of retained earnings and net investment is financed by bonds. Let $B_{t}$ be the number of bonds per capita outstanding at time $t$, each paying $r_{t}$ units of output at time $t$. The netof-interest cash flow of the firm is

$$
f\left(k_{t}\right)-k_{t} x_{t}\left(1+h\left(x_{t}\right)\right)-w_{t}-r_{t} B_{t}
$$

The dividend $\pi_{t}$ distributed by the firm is output less depreciation, wages and interest:

$$
\pi_{t}=f\left(k_{t}\right)-k_{t} \delta(1+h(\delta))-w_{t}-r_{t} B_{t}
$$

The excess of dividends over net-of-interest cash flow must be financed by issuing new bonds: 
3.6

$$
\dot{\mathrm{B}}_{\mathrm{t}}=\mathrm{k}_{\mathrm{t}}\left[\mathrm{x}_{\mathrm{t}}\left(1+\mathrm{h}\left(\mathrm{x}_{\mathrm{t}}\right)\right)-\delta(1+\mathrm{h}(\delta))\right]
$$

There is a simple relation between the value of the owners' equity, the value of the firm's liabilities, the shadow value $q$ and the capital stock:

3.7

$$
q_{t} k_{t}=v_{t}=B_{t}+\int_{t}^{\infty} \pi_{s} \rho_{s} d s
$$

The second equality simply reflects the fact that the value of the firm is equal to the sum of its liabilities and owners ${ }^{p}$ equity and that it is independent of the method of financing. The first equality is more interesting; it says that "average q" and "marginal q" are equal, implying therefore a simple relation between investment and the observable average value. This equality depends on the production and investment installation functions being linearly homogeneous in labor, capital and investment. The proof is a special case of Hayashi [3].

\section{Utility maximization by consumers}

Each consumer supplies one unit of labor inelastically and receives a wage $w_{t}$. His only decision problem is to choose a sequence of consumption which maximizes the present value of utility:

$$
\int_{0}^{\infty} U\left(c_{t}\right) e^{-\beta t} d t
$$


The wealth constraint can be expressed as:

$$
\dot{B}_{t}=\pi_{t}+w_{t}+r_{t} B_{t}-c_{t} ; \lim _{t \rightarrow \infty} \rho_{t} B_{t}=0
$$

Income is the sum of wages, interest on bond holdings and dividends. It must be allocated either to consumption or to savings in the form of bonds, $\dot{\mathrm{B}}_{t}$. The Hamiltonian for this problem is:

$$
e^{-B t}\left[U\left(c_{t}\right)+\lambda_{t}\left(\pi_{t}+w_{t}+r_{t} B_{t}-c_{t}\right)\right]
$$

The optimality conditions are ${ }^{3}$ :

$3.8 \quad U^{\prime}\left(c_{t}\right)=\lambda_{t}$

$3.9 \quad \dot{\lambda}_{t}=\left(\beta-r_{t}\right) \lambda_{t}$

$3.10 \quad \lim _{t \rightarrow \infty} e^{-\beta t} \lambda_{t}=0$

Equations 3.8 and 3.9 determine the path of the rate of change of marginal utility. The level of this path is determined by the wealth constraint, which can be written as

$$
\int_{0}^{\infty} c_{t} \rho_{t} d t=v+v^{*} ; v=q k, v^{*} \equiv \int_{0}^{\infty} w_{t} \rho_{t} d t
$$

This shows that consumption depends on both nonhuman and human wealth. It also shows how $q$ enters both the investment decision of firms and the consumption decision of consumers. 
The condition for equilibrium in the goods market is that output equals spending:

$3.11 \quad f\left(k_{t}\right)=c_{t}+k_{t} x_{t}\left(1+h\left(x_{t}\right)\right)$

This condition, together with the anticipation that this condition will hold at all future times, determines at any instant the complete term structure of interest rates. The temporary equilibrium of this economy is similar to the IS relation of closed-economy macroeconomic models. Aggregate demand is the sum of consumption and investment. Consumption is an increasing function of total wealth in the spirit of Metzler. Investment is an increasing function of the ratio of market value to capital in the spirit of Tobin. Aggregate demand is brought into equality with aggregate supply, in this full employment model, by the endogenous adjustment of the term structure of interest rates. 


\section{Equivalence of the Two Economies}

To show equivalence, we must first show that the equations of motion of the market economy replicate those of the centralized one. Consider the two shadow prices of the market economy, $\lambda_{t}$, associated with consumption and $q_{t}$, associated with investment. Define $y_{t} \equiv q_{t} \lambda_{t}$. From (3.1) and (3.8),

$4.1 \quad y_{t}=U^{\prime}\left(c_{t}\right) H\left(x_{t}\right)$

This is identical to (2.5). Differentiating with respect to time:

$4.2 \quad \dot{y}_{t}=\dot{\lambda}_{t} q_{t}+\lambda_{t} \dot{q}_{t}$

Substituting (3.2) for $\dot{q}_{t}$, (3.9) for $\dot{\lambda}_{t}$, we obtain

$4.3 \quad \dot{y}_{t}=(B+\delta) \lambda_{t} q_{t}-\lambda_{t}\left[f^{\prime}\left(k_{t}\right)+x_{t}^{2} h^{\prime}\left(x_{t}\right)\right]$

This gives an expression in which interest rates do not appear. Using (3.8) and the definition of y gives:

$4.4 \quad \dot{y}_{t}=(B+\delta) y_{t}-U^{\prime}\left(c_{t}\right)\left[f^{\prime}\left(k_{t}\right)+x_{t}^{2} h^{\prime}\left(x_{t}\right)\right]$

This is identical to (2.6) in the centralized economy. The shadow price $y_{t}$ is therefore the product of the consumption and investment shadow prices. We must now show that the transversality conditions of the market economy imply the transversality condition of the centralized economy. Equations (3.3) for $q_{t}$ and (3.9) for $\lambda_{t}$ imply respectively 
$\begin{array}{ll}\text { 4.5a } & \lim _{t \rightarrow \infty} \frac{\dot{q}_{t}}{q_{t}}+\lim _{t \rightarrow \infty} \frac{\dot{k}_{t}}{k_{t}}<\lim _{t \rightarrow \infty} r_{t}, \text { as } \frac{\dot{\rho}_{t}}{\rho_{t}}=-r_{t} \\ 4.5 b \quad & \lim _{t \rightarrow \infty} \frac{\dot{\lambda}_{t}}{\lambda_{t}}=\beta-\lim _{t \rightarrow \infty} r_{t}\end{array}$

Note that both transversality conditions depend on the market-determined interest rate. Differentiate logarithmically $y_{t} k_{t}=q_{t} \lambda_{t} k_{t}$ with respect to time:

$4.6 \quad \frac{\dot{y}_{t}}{y_{t}}+\frac{\dot{k}_{t}}{k_{t}}=\frac{\dot{q}_{t}}{q_{t}}+\frac{\dot{\lambda}_{t}}{\lambda_{t}}+\frac{\dot{k}_{t}}{k_{t}}$

which implies $\lim _{t \rightarrow \infty}\left(\frac{\dot{y}_{t}}{y_{t}}+\frac{\dot{k}_{t}}{k_{t}}\right)<\beta$ from the two conditions above. This is the transversality condition (2.7) of the centralized economy.

The equivalence between the two economies is hardly surprising. It is nevertheless very useful as it allows, when studying the effects of various shocks or policies, to use the equations of motion of the centralized economy with its unique shadow price rather than the equations of motion of the market economy with the two shadow prices which themselves depend on market-determined interest rates. This is what we do now, using this equivalence to study the effects of various fiscal policies. 


\section{Fiscal Policies and Technological Shifts}

Extending Hall's [2] analysis from the standard optimal growth model, we study the following fiscal policies: a head tax--or lump-sum tax--in amount $\theta_{0}$ per agent; a proportional tax on gross output $f(k)$, at rate $\theta_{1}$; a proportional tax on profit ${ }^{4}(\mathrm{f}(\mathrm{k})-w)$, at rate $\theta_{2}$; a proportional tax on net output $(f(k)-k x(1+h(x)))$, at rate $\theta_{3}$, which can also be interpreted as a tax on consumption; finally an investment tax credit, which we treat as a proportional subsidy to investment spending $\mathrm{kx}(1+\mathrm{h}(\mathrm{x}))$, at rate $\theta_{4^{\circ}}$. All these policies are balanced budget policies and are either refunded as lump-sum taxes or used for government spending in a way which does not affect private investment or consumption decisions.

We now consider three types of technological shifts, a, b, and $\sigma$ which affect the production and installation functions. These functions become $(1-a) f(k)-\sigma$ and $(1-b) k x(1+h(x))$ respectively.

It is now straightforward to show the equivalence of each fiscal policy to a combination of these technological shifts. These equivalences are given in Table I. If, as in the third column of the table, the government uses tax revenue to purchase current output, then the output available to the private sector declines by the amount of the tax revenue. Alternatively, if the government redistributes tax revenue via lump-sum rebates, as in column two, then output available to the private sector is unchanged by the imposition of taxes. To study the effect of a policy in the decentralized economy, we may instead study the effects of the equivalent combination of technological shifts in the centralized economy. Once the behavior of consumption, investment and output is characterized, it is relatively easy to deduce the market clearing sequence of interest rates in the market economy. 
Table I Equivalence of fiscal policies and technological shifts

\begin{tabular}{|c|c|c|}
\hline Tax in combination with: & lump-sum rebates & government spending \\
\hline Head $\operatorname{tax}, \theta_{0}$ & - & $\sigma=\theta_{0}$ \\
\hline Gross output tax, rate $\theta_{1}$ & $a=\theta_{1} ; \sigma=-\theta_{1} f(k)$ & $a=\theta_{1}$ \\
\hline Profit tax, rate $\theta_{2}$ & $a=\theta_{2} ; \sigma=-\theta_{2} f(k)$ & $a=\theta_{2} ; \sigma=-\theta_{2} \mathrm{kf}^{\prime}(\mathrm{k})$ \\
\hline $\begin{array}{l}\text { Net output tax, rate } \theta_{3} \\
\text { (consumption tax) }\end{array}$ & $\begin{array}{l}a=b=\theta_{3} \\
\sigma=-\theta_{3}(f(k)-k x(1+h(x)))\end{array}$ & $a=b=\theta_{3}$ \\
\hline Investment subsidy, rate $\theta_{4}$ & $\begin{array}{l}b=\theta_{4} \\
\sigma=\theta_{4} \mathrm{kx}(1+\mathrm{h}(\mathrm{x}))\end{array}$ & $b=\theta_{4}$ \\
\hline
\end{tabular}


The relevant equations, including the equations of motion, of the centralized economy are direct extensions of (2.2) to (2.9):

$5.1 \quad(1-a) f(k)-(1-b) k x(1+h(x))-\sigma=c$

$5.2 \quad U^{\prime}(c) H(x)(1-b)=y$

$5.3 \quad \dot{y}=(\beta+\delta) y-U^{\prime}(c)\left[(1-a) f^{\prime}(k)+(1-b) x^{2} h^{\prime}(x)\right]$

$5.4 \quad \dot{k}=k(x-\delta)$

$5.5 \quad\left[H^{\prime}(x)-\frac{U^{\prime \prime}(c)}{U^{\prime}(c)}(1-b)(H(x))^{2} k\right] \dot{x}=$

$$
\begin{aligned}
& {\left[(\beta+\delta) H(x)-x^{2} h^{\prime}(x)-\frac{(1-a)}{(1-b)} f^{\prime}(k)\right]} \\
& -\frac{U^{\prime \prime}(c)}{U^{\prime}(c)} H(x)\left[(1-a) f^{\prime}(k)-(1-b) x(1+h(x))\right] \dot{k}
\end{aligned}
$$

Consider first the steady-state effects of these policies. Setting $\dot{\mathrm{x}}=\dot{\mathrm{k}}=0$ gives, from (5.4) and (5.5),

$$
f^{\prime}\left(k_{s S}\right)=\frac{(1-b)}{(1-a)}\left[(\beta+\delta) H(\delta)-\delta^{2} h^{\prime}(\delta)\right]
$$

Two of the policies, the head tax $(a=b=0)$ and the net output tax $\left(a=b=\theta_{3}\right)$, have no effect on the steady-state capital stock; their full effect is on consumption which decreases by the amount of tax. The investment subsidy $\left(\mathrm{a}=0, \mathrm{~b}=\theta_{4}\right)$ increases the capital stock while both the gross output and profit taxes $\left(a=\theta_{1}\right.$ or $\left.\theta_{2} ; b=0\right)$ decrease it. 
The more interesting effects are the dynamic effects. Going through all dynamic effects for all policies would exhaust the reader's patience. In the next section we consider two simple policies--a head tax and a consumption tax--both used to finance government spending. 


\section{Dynamic Effects of Lump-sum and Consumption Taxes}

\section{Lump-sum taxes}

As shown in the previous section, the steady-state capital stock is independent of changes in lump-sum taxes. Thus, if the economy is in steady state when there occurs a permanent unanticipated increase in lump-sum taxes of $\Delta \sigma$, consumption immediately and permanently decreases by $\Delta \sigma$. There is no effect on investment, or the capital stock at any point of time.

Now consider an economy which is outside of steady state, for example at point $A$ in Figure III, when there is an unanticipated permanent increase in $\sigma$. Whether the equations of motion (5.4) and (5.5) of ( $x, k)$ are affected depends on whether $-\frac{U^{\prime \prime}(c)}{U^{\prime}(c)}$, the coefficient of absolute curvature --or absolute risk aversion in a different context--which we denote by $\alpha(\mathrm{c})$, is affected by a change in $c$.

Suppose $\alpha(\mathrm{c})$ is constant, i.e. $\alpha^{\prime}(\mathrm{c}) \cong 0$. The time path of marginal rates of substitution $\frac{U^{\prime}\left(c_{s}\right)}{U^{\prime}\left(c_{t}\right)} \forall s, t$ is unaffected by an equal absolute decrease in consumption of $\Delta \sigma$ at every point in time. Thus, if $\alpha^{\prime}(c) \equiv 0$, the effect of a permanent change in $\sigma$ is to crowd out private consumption immediately and permanently by $100 \%$, with no effect on capital accumulation .

Suppose now $\alpha^{\prime}(\mathrm{c})>0 \forall \mathrm{c}$, so that an equal absolute decline in consumption increases the marginal utility of consumption by more when consumption is high. Consider the case in which the steady state is approached from the northwest, such as point $A$ in Figure III and consumption is increasing over time. An equal absolute decline in consumption would therefore increase future marginal utility more than present marginal utility; this in turn would lead consumers to increase future consumption. 
This suggests that in this case, the increase $\Delta \sigma$ will initially crowd out consumption by more than $100 \%$ and therefore increase investment. A proof is given in Appendix $B$.

Let us refer to the path which would have been followed in the absence of the fiscal change as the "original" path. As the steady-state capital stock is unaffected, investment must decrease below its original path during some time. At the time when investment has the same value as on the original path, capital and output are higher and thus consumption plus taxes must be higher than on the original path. Thus, consumption must before that time have increased faster than on the original path, and must increase more slowly after that time. In the decentralized economy, this is accomplished by a twist in the term structure of interest rates, with an increase in $r_{t}$ in the short run and a decrease in $r_{t}$ in the long $r u n$.

The opposite argument holds if the steady state is approached from the southeast, with decreasing consumption. The argument and conclusions are reversed if $\alpha^{\prime}(c)<0$, i.e. if the utility has decreasing absolute curvature (risk aversion).

We now consider the effects of an anticipated increase in lump-sum taxes. For convenience, we assume that the economy is initially in steady state, that $a=b=0$ and that $\alpha^{\prime}(c) \equiv 0$. Relaxing these restrictions complicates the exposition but changes nothing of substance.

It is easier to understand the effects by working backward in time. Suppose that the increase is implemented at time $t *$ but known as of time $\mathrm{t}_{0}<\mathrm{t}^{*}$. At time $\mathrm{t}^{*}, \mathrm{y}$, the costate variable cannot have an anticipated discontinuity ${ }^{5}$; therefore $c$ and $x$ have to satisfy the following two relations: 


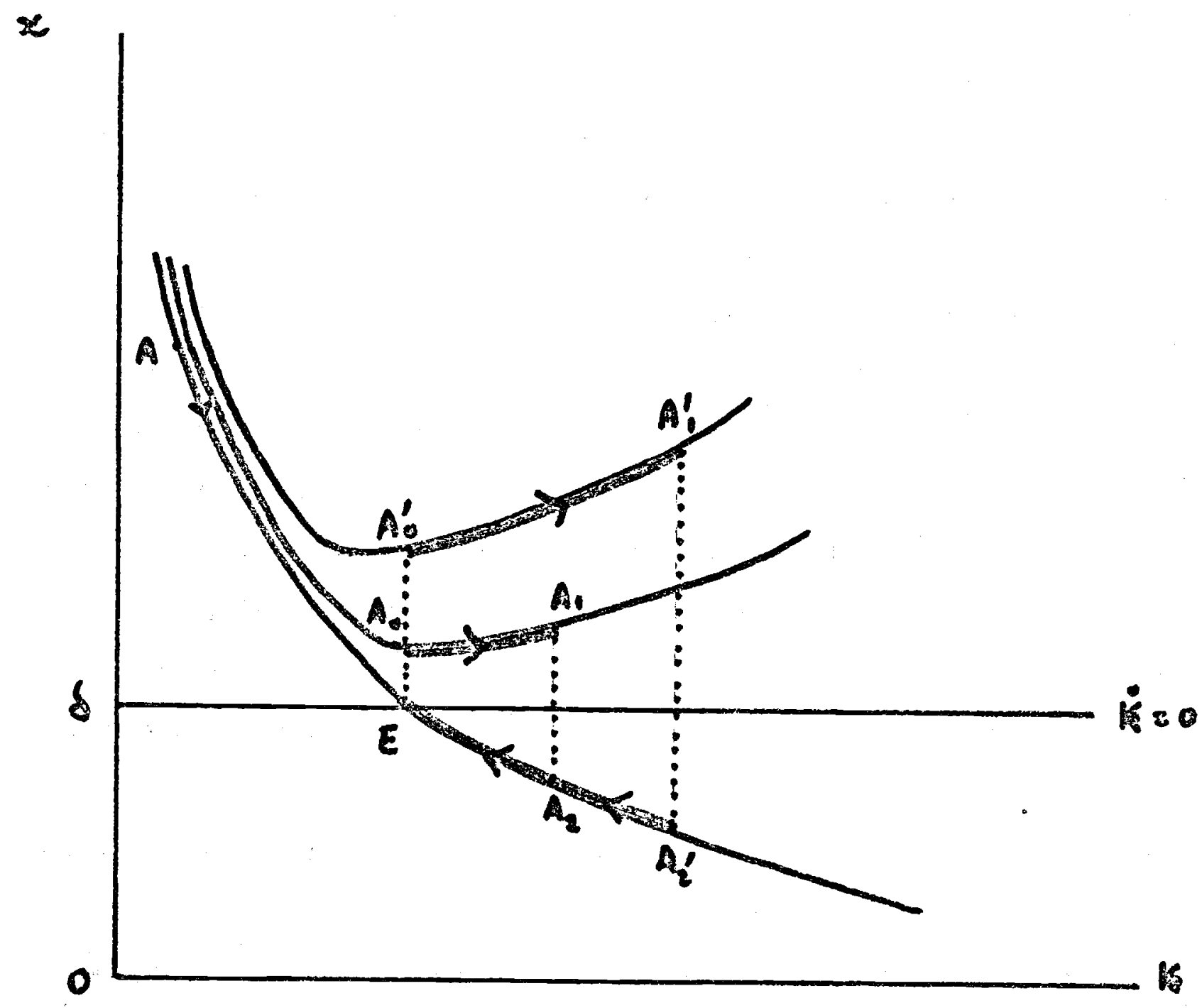

Figure III 


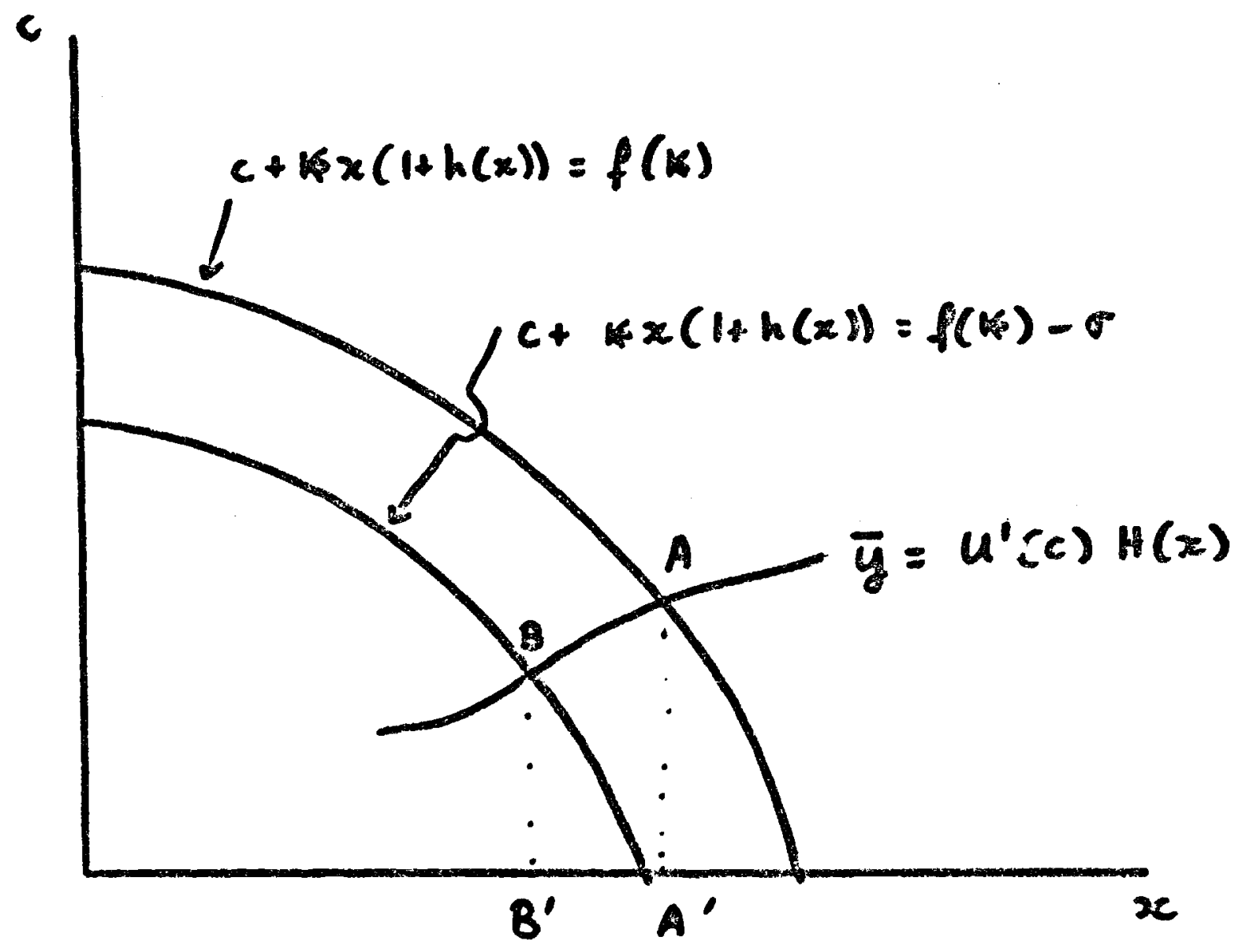

Figure II 


$$
\begin{aligned}
& y_{t * *}=U^{\prime}\left(c_{t *}\right) H\left(x_{t *}\right) \\
& c_{t *}+k_{t *} x_{t *}\left(1+h\left(x_{t * *}\right)\right)=f\left(k_{t *}\right)-\sigma
\end{aligned}
$$

These two loci are drawn in Figure IV. An increase in $\sigma$ causes a downward jump in both $c$ and $x$. The relative size of jumps in $c$ and $x$ depends on the ratio of convexities $H^{\prime}(x) / U^{\prime \prime}(c)$. If there are no adjustment costs, the adjustment will come entirely from investment. If utility is nearly linear, most of the adjustment will be in consumption.

Given the assumption that $\alpha^{\prime}(c) \equiv 0$, the equations of motion in the $(k, x)$ plane are not affected by the change in policy. Two possible paths, corresponding to two different jumps in $\mathrm{x}$ at time $\mathrm{t}^{*}$, are characterized in Figure III. They are $\mathrm{EA}_{0} \mathrm{~A}_{1} \mathrm{~A}_{2} \mathrm{E}$ and $\mathrm{EA}_{0}^{\prime} \mathrm{A}_{1}^{\prime} \mathrm{A}_{2}^{\prime} \mathrm{E}$.

Unless utility is linear, the anticipation of the tax increase will reduce consumption and increase investment. When the tax increase takes place, it does not fall entirely on consumption but falls also on investment. Net investment is negative and capital is decumulated back to its steady state level. Consumption keeps decreasing after the increase in taxes until it reaches its lower steady state value.

The temporary accumulation of capital smooths the effects of the tax on consumption. Because of adjustment costs, the smoothing is not complete and there is a discontinuous fall in consumption at the time of the tax increase. In the absence of adjustment costs, there would be no such fall and consumption would decrease continuously from the time of the announcement. What is the associated sequence of rates which will replicate this path of consumption and investment? The interest rate at time t* must be infinitely negative for an instant in order to generate the discontinuous 
decreases in consumption and investment. (This unappealing feature is due to the discontinuity in $\sigma$ and could be eliminated either by moving to discrete time as in Hall [2] or by making $\sigma(t)$ continuous.) From Figure III and equation (3.9), as consumption may be increasing or decreasing between $t_{0}$ and $t^{*}$, and is decreasing after $t^{*}$, short rates may be either above or below their initial value of $\beta$ between $t_{0}$ and $t *$, and are lower than $\beta$ after $t \stackrel{t}{*}$.

In summary, a permanent increase in lump-sum taxes has no steady-state effect, except on consumption which it crowds out completely. If the increase is unanticipated, it crowds out consumption instantaneously by $100 \%$ if the economy is initially in steady state; if the capital stock is below steady state, the immediate effect is to decrease consumption by more than, less than, or exactly 100\%--and increase, decrease or leave unchanged investment--depending on whether $-\frac{U^{\prime \prime}(c)}{U^{\prime}(c)}$ is an increasing, decreasing or constant function of $c$. If the increase in taxes is anticipated, the anticipation itself increases investment and decreases consumption; the implementation decreases both investment and consumption. This reflects the desire of consumers to smooth the path of anticipated consumption.

\section{Consumption taxes}

The effects of a permanent net output, or consumption, tax are very similar to the effects of a lump-sum tax. They will be stated with only a sketch of a proof given in the appendix. Some of the results below assume that $\sigma=0$.

An unanticipated permanent increase in the tax rate completely crowds out consumption and has no effect on investment and the capital stock if the economy is initially in steady state. If the economy is 
not initially in steady state, the dynamic behavior depends on the coefficient of relative curvature $\xi(c) \equiv-\frac{U^{\prime \prime}(c) c}{U^{\prime}(c)}$. If the capital stock is lower than its steady-state value, a permanent unanticipated increase in the tax will crowd out private consumption initially by more than, less than or exactly $100 \%$ depending on whether $\xi^{\prime}(c)$ is positive, negative or zero.

The effects of an anticipated increase in the tax rate depend on the value of $\xi(c)$. If $\xi(c)$ is identically equal to unity, i.e. the utility function is logarthmic, there is no anticipation effect: consumption does not change before the change in the tax and falls when the tax is imposed. This paradoxical result was noted by Hall and we borrow his explanation. If we view the tax as a consumption tax, the announcement has two effects, a substitution effect in favor of consumption before the tax increase and an income effect which tends to decrease current consumption. If $\xi=1$, the two effects cancel each other. In general, consumption decreases, remains unchanged, or increases depending on whether $\xi(c)$ is greater than, less than or equal to unity. 


\section{Conclusion}

We have developed a dynamic model of saving and investment based on competitive optimizing consumers and firms. In the short-run equilibrium of this mode1, consumption is an increasing function of total wealth and investment is an increasing function of the shadow price of installed capital relative to the price of output. The determination of these two components of aggregate demand is consistent with many short-run macro models. Put differently, this paper provides a consistent intertemporal framework in which to embed standard IS relations, and thus to characterize more fully the dynamic effects of shocks or policies. 
Appendix A. Dynamics in the $(k, x)$ space

The equations of motion are given by (2.3) and (2.9):

$$
\begin{aligned}
& \dot{k}=k(x-\delta) \quad \text { and } \\
& A_{1} \dot{x}=A_{2}+A_{3} \dot{k} \quad \text { where } \\
& A_{1} \equiv H^{\prime}(x)-\frac{U^{\prime \prime}(c)}{U^{\prime}(c)}(H(x))^{2} k>0 \\
& A_{2} \equiv(B+\delta) H(x)-x^{2} h^{\prime}(x)-f^{\prime}(k) \\
& A_{3} \equiv-\frac{U^{\prime \prime}(c)}{U^{\prime}(c)} H(x)\left[f^{\prime}(k)-x(1+h(x))\right]
\end{aligned}
$$

Consider the locus $\mathrm{A}_{2}=0$. It is such that

$$
\left.\frac{\mathrm{dk}}{\mathrm{dx}}\right|_{\mathrm{A}_{2}=0}=\frac{(\beta+\delta-\mathrm{x}) \mathrm{H}^{\prime}(\mathrm{x})}{\mathrm{f}^{\prime \prime}(\mathrm{k})} \geq 0 \text { as } \quad \mathrm{x} \geq \frac{2}{<} \beta+\delta
$$

Consider the locus $A_{3}=0$. It is such that

$$
\left.\frac{\mathrm{dx}}{\mathrm{dk}}\right|_{\mathrm{A}_{3}=0}=\frac{\mathrm{f}^{\prime \prime}(\mathrm{k})}{\mathrm{H}(\mathrm{x})}<0
$$

We can draw in Figure $V$, the loci $\dot{k}=0, A_{2}=0$ and $A_{3}=0$. Note that $\left(A_{2}=0\right)$ and $\left(A_{3}=0\right)$ have the same value of $k$ for $x=\beta+\delta$, and that $\left(\mathrm{A}_{2}=0\right)$ and $(\dot{\mathrm{k}}=0)$ intersect at the steady state $\mathrm{E}$. The three loci divide the $(k, x)$ plane into seven regions. Table II gives the signs of the components of $x,\left(A_{2}, A_{3}, \dot{k}\right)$ for each region. It follows from Table II that $\dot{x}=0$ lies in regions II, III and VI and passes through $B$. 


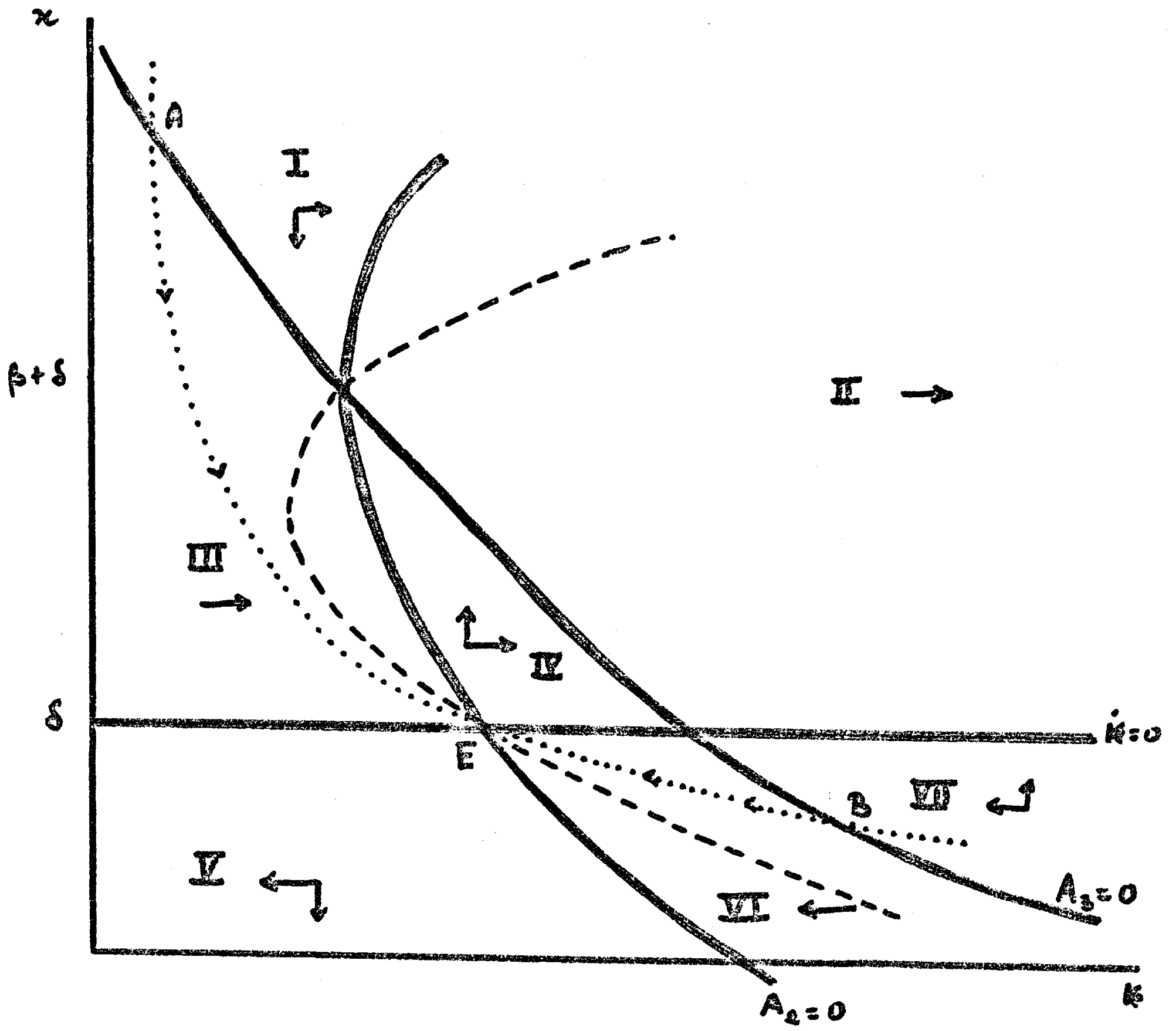

Figure I. 
It also follows that the equilibrium is a saddle point equilibrium as drawn in Figures $I$ and II in the text.

Table II

\begin{tabular}{c|ccccc} 
Region & Sign of : & $\mathrm{A}_{2}$ & $\mathrm{~A}_{3}$ & $\dot{\mathrm{k}}$ & $\dot{\mathrm{x}}$ \\
\hline I & & - & - & + & - \\
II & & + & - & + & $?$ \\
III & & - & + & + & $?$ \\
IV & + & + & + & + \\
V & & - & + & - & - \\
VI & & + & + & - & $?$ \\
VII & & + & - & - & +
\end{tabular}


Appendix B. Effects of an unanticipated permanent head tax outside of steady state

We consider the case in which $\alpha^{\prime}(c)>0$ and the steady state is reached from the northwest so that consumption is increasing. This case

corresponds to region III in Figure $V$.

We first show that for any $(k, x)$ point in region III, including the stable arm, $\dot{x}$ is now more negative than before the increase in $\sigma, d \sigma$. From (5.5) in the text:

$$
\begin{aligned}
\left.d \dot{x}\right|_{k, x}= & {\left[H^{\prime}(x)+\alpha(c)(1-b)(H(x))^{2} k\right]^{-1} \times } \\
& \left\{-\alpha^{\prime}(c) H(x)\left[(1-a) f^{\prime}(k)-(1-b) x(1+h(x))\right] k(x-\delta)\right. \\
& \left.+\alpha^{\prime}(c)(1-b)(H(x))^{2} k \dot{x}\right\} d \sigma
\end{aligned}
$$

From Table II, $\left.d \dot{x}\right|_{k, x}<0$ in region III.

For any point in region III below the original stable arm, $x$ falls too rapidly to reach $E$ under the original laws of motion. Since $x$ falls even more rapidly under the new laws of motion, the new stable path to $E$ cannot lie below the original stable path. Therefore the new stable path lies above the original stable path.

The case in which the steady state is approached from the southeast and the cases associated with $\alpha^{\prime}(c)<0$ can be analyzed in a similar way. 
Appendix C. Dynamic effects of a permanent consumption tax

If $\sigma=0$ and $a=b,(5.5)$ can be rewritten as:

$$
\begin{aligned}
& {\left[H^{\prime}(x)+(f(k)-k x(1+h(x)))^{-1}(H(x))^{2} k \xi(c)\right] \dot{x}=} \\
& {\left[(B+\delta) H(x)-x^{2} h^{\prime}(x)-f^{\prime}(k)\right]+} \\
& {[f(k)-k x(1+h(x))]^{-1}\left(f^{\prime}(k)-x(1+h(x))\right) H(x) \xi(c) \dot{k}} \\
& \xi(c) \equiv-\frac{c U^{\prime \prime}(c)}{U^{\prime}(c)}
\end{aligned}
$$

Thus if $\xi^{\prime}(c)=0$, the equations of motion of $k$ and $x$ are unaffected by a change in the consumption tax. If $\xi^{\prime}(c) \neq 0$, an analysis similar to the one used in Appendix B can be used to characterize the shift in the stable arm.

To characterize the effects of an anticipated increase in the tax at time $t^{*}$ say, consider the movements in $c$ and $x$ at time $t * . c$ and $x$ satisfy (5.1) and (5.2), with $\sigma=0, a=b$. Differentiating with respect to $c, x$ and a gives:

$$
\begin{aligned}
& \mathrm{dx}=\Delta^{-1} \mathrm{U}^{\prime}(\mathrm{c}) \mathrm{H}(\mathrm{x})[1-\xi(\mathrm{c})] \\
& \mathrm{dc}=\Delta^{-1}\left[-\mathrm{U}^{\prime}(\mathrm{c}) \mathrm{H}^{\prime}(\mathrm{x}) c-(1-\mathrm{a}) \mathrm{k}(\mathrm{H}(\mathrm{x}))^{2} \mathrm{U}^{\prime}(\mathrm{c})\right]
\end{aligned}
$$

where

$$
\Delta \equiv U^{\prime}(c) H^{\prime}(x)(1-a)-U^{\prime \prime}(c)(H(x))^{2}(1-a)^{2} k
$$

If $\xi(c)=1$, then $\mathrm{dx}=0$. If $\xi(\mathrm{c}) \equiv 1$, then $\xi^{\prime}(\mathrm{c}) \equiv 0$ and the equations of motion are unchanged; thus if $x$ does not jump at time $t *$, 
it remains constant for al1 $t$. If $\xi(c) \neq 1$, then $d x \neq 0$ and the results given in the text follow from the phase diagram. 


\section{$\underline{\text { References }}$}

[1] Eisner, R. and R. H. Strotz: "Determinants of Business Investment," in Impacts of Monetary Policy, Prentice Hall, 1963, 59-337.

[2] Hall, R.: "The Dynamic Effects of Fiscal Policy in an Economy with Foresight," Review of Economic Studies, April 1971, 229-244.

[3] Hayashi, F.: "Tobin's q, Rational Expectations and Optimal Investment Rule," forthcoming Econometrica.

[4] Kemp, M. C. and N. V. Long: "Optimal Control Problems with Integrands Discontinuous with Respect to Time," Economic Record, 53, September $1977,405-420$.

[5] Lucas, R.: "Adjustment Costs and the Theory of Supply," Journal of Political Economy, 75, August 1967, 321-334.

[6] Metzler, L.: "Wealth, Saving and the Rate of Interest," Journal of Political Economy, 49, April 1951, 93-116.

[7] Srinivasan, T. N.: "Optimal Savings in a Two Sector Model of Growth," Econometrica, 32, 1964, 358-373.

[8] Tobin, J.: "Monetary Policies and the Economy: The Transmission Mechanism," Southern Economic Journal, 44, January 1978, $421-431$

[9] Uzawa, H.: "Optimal Growth in a Two Sector Model of Capital Accumulation," Review of Economic Studies, 31, 1964, 1-24.

[10] Weitzman, M.: "Duality Theory for Infinite Horizon Convex Models," Management Science, 19-7, March 1973, 783-789. 
Footnotes

1. This paper was written while the first author was at the University of Chicago. We thank Fumio Hayashi, Frederic Mishkin, Michael Mussa and the members of the Money and Banking Workshop at the University of Chicago for their comments. Financial support from the Sloan Foundation and the National Science Foundation is gratefully acknowledged.

2. This formalization of adjustment costs is based on Eisner and Strotz [1] and Lucas [5].

3. This problem satisfies the conditions of Weitzman's theorem [10], so that these conditions are necessary and sufficient.

4. Hall does not have labor explicitly as a factor of production, so that he does not distinguish between the gross output and profit taxes.

5. This follows from theorem 2 in Kemp and Long [4]. 